\title{
Isolated plagiocephaly
}

INSERM

\section{Source}

INSERM. (1999). Orphanet: an online rare disease and orphan drug data base. Isolated plagiocephaly. ORPHA:35098

Isolated synostotic plagiocephaly (SP) is a form of nonsyndromic craniosynostosis characterized by premature fusion of one coronal suture leading to skull deformity and facial asymmetry. 